Research Article

\title{
Freeze-Thaw Performance of Silt Sand Treated with Lignin
}

\author{
Fu Zhu $\mathbb{D}$, Jiayu Li, Wenhao Jiang, Shuang Zhang $\mathbb{D}$, and Weizhi Dong $\mathbb{D}$ \\ School of Transportation Science and Engineering, Jilin Jianzhu University, Changchun 130118, China \\ Correspondence should be addressed to Weizhi Dong; dongweizhi1022@126.com
}

Received 28 December 2020; Revised 28 January 2021; Accepted 20 February 2021; Published 1 March 2021

Academic Editor: Xun Xi

Copyright (C) $2021 \mathrm{Fu}$ Zhu et al. This is an open access article distributed under the Creative Commons Attribution License, which permits unrestricted use, distribution, and reproduction in any medium, provided the original work is properly cited.

\begin{abstract}
In cold regions, freeze-thaw action poses a significant hazard to road engineering. In order to avoid the adverse effects of inorganic materials on soil modification, we applied lignin, which is an environmentally friendly and organic polymer, to improve the silt sand from cold regions. The significance of this study is to facilitate the better application of lignin. The macroscopic engineering properties of the soil showed that, before freeze-thaw, as the lignin content increased, thermal conductivity and permeability decreased, $\mathrm{pH}$ first increased rapidly and then stabilized between 10 and 11, and dynamic resilient modulus first increased then decreased; after freeze-thaw, as lignin content increased, thermal conductivity and permeability decreased, and dynamic resilient modulus first increased then decreased. The freeze-thaw action reduced the thermal conductivity and dynamic resilient modulus of silt sand treated with lignin and increased its permeability. The test results of soil microstructure indicated that, before freezethaw, the silt sand and silt sand treated with lignin were structurally compact; after freeze-thaw, the silt sand showed numerous cracks and pores and had a loose soil structure, whereas the silt sand treated with lignin showed fewer cracks and pores, and its soil structure was more compact under the encapsulation and filling action of cementitious materials. No new chemical elements, mineral components, or functional groups were produced when lignin was mixed with silt sand. The mechanism by which lignin improved the macroengineering properties of silt sand involved the cementitious material produced by the interaction between lignin and soil minerals, which encapsulated the soil particles and filled the interparticle pores. Research results can provide a theoretical reference for engineering application of lignin in cold regions.
\end{abstract}

\section{Introduction}

In the harsh cold region of northern China, the frost damage of roads can cause significant harm to their structures, especially to the subgrade and pavement. The design of advanced pavements, in particular, places a special emphasis on addressing the problem of freezing and on reducing or eliminating some of the adverse consequences of frost damage through correct design measures. The freezing process causes changes in the moisture content, compactness, structure, and bearing capacity of soil. In frozen soils, frost heave occurs due to the transformation of accumulated moisture into ice lenses. Frost heave is a phenomenon in which water accumulates at the frost line and precipitates as ice crystals after resisting external pressure. The main structure involved in the occurrence of frost heave is within thin-film water, and the process is continuous. When thinfilm water freezes, it generates an absorbent force that can attract the surrounding moisture, and the freezing of water that can generate this absorbent force is known as precipitation icing, which can result in the formation of ice crystals. Due to differences in soil compactness and water content, the formation of ice crystals often causes uneven frost heave of the subgrade, which can damage the asphalt mixture pavement. Therefore, mechanical properties tests of asphalt mixture under freeze-thaw cycles are often carried out in cold regions [1-3]. During the thawing period, frost damage is even more severe in subsoil that have undergone severe freezing. In particular, the bearing capacity of subgrades composed of frost-susceptible material will be greatly reduced, and the pavement will be damaged by fatigue under the repeated action of traffic loading.

In recent years, a number of researchers have attempted to solve the problem of frost damage in road engineering for cold regions by mixing inorganic modifiers, such as lime, cement, and fly ash, into soil to eliminate the formation of 
ice lenses [4-10]. By filling or compacting the pores with the modifiers, the moisture will be prevented from moving, which will stop the formation of ice lenses. Although inorganic modifiers can effectively improve the frost resistance of soil and reduce the occurrence of frost damage in road engineering for cold regions, they can also cause certain hazards to the surrounding environment, such as altering the $\mathrm{pH}$ value of the soil, affecting its water-holding capacity and vegetation growth, and reducing the service life of soil structures [11-13]. Therefore, the development of new, effective, and environmentally friendly soil modifiers has become an urgent need in the field of road engineering for cold regions. The silt sand is widely distributed in Jilin Province, China, and since the poor compactness and easy dust of this soil does not meet the specification requirements, it must be amended to be used for subgrade filling. Lignin is a high-molecular-weight polymer with an organic chemical composition and does not pollute the soil environment, which has been applied in subgrade soil improvement. A number of researchers have studied the use of lignin in soil improvement and have concluded that lignin can effectively improve the strength, stiffness, permeability, and other engineering properties of clay and silt soils, while also having a significant effect on their microstructures [14-20]. However, there is a lack of relevant studies on the interaction between lignin and soil under freeze-thaw conditions, and the microscopic mechanisms of its frost resistance.

In this paper, we investigated the effects of freezethaw and lignin content on the thermal conductivity, dynamic resilient modulus, and permeability of the soil, examined the effects of freeze-thaw and lignin on soil microstructure using scanning electron microscopy (SEM), and analyzed the effects of lignin on soil chemical elements, mineral composition, and functional groups with the aid of energy-dispersive X-ray spectroscopy (EDS), X-ray diffraction (XRD), and Fourier transform infrared spectroscopy (FTIR), based on which we were able to establish the relationship between the macroengineering properties and the microstructural characteristics of soil treated with lignin under freeze-thaw conditions.

\section{Materials and Methods}

2.1. Raw Materials. Soil samples were taken from an expressway project in the west part of Jilin Province, and the relative density of soil particles was 2.64 . Particle analysis revealed that the particle content was $11.18 \%$ for particles $>0.025 \mathrm{~mm}, 56.54 \%$ for $0.075 \mathrm{~mm}-0.025 \mathrm{~mm}, 20.61 \%$ for $0.005 \mathrm{~mm}-0.075 \mathrm{~mm}$, and $11.67 \%$ for $<0.005 \mathrm{~mm}$. A $76 \mathrm{~g}$ cone penetrometer for combined liquid-plastic limit testing was used to determine the limiting moisture content of the soil samples, which revealed that the $10 \mathrm{~mm}$ liquid limit was $15.6 \%$, the $2 \mathrm{~mm}$ plastic limit was $7.4 \%$, and the plasticity index was calculated to be 8.2.

The experimental lignin was obtained from a paper mill in Luohe City, Henan Province, and was yellowish-brown in color (Figure 1). It was a solid powder, contained a small

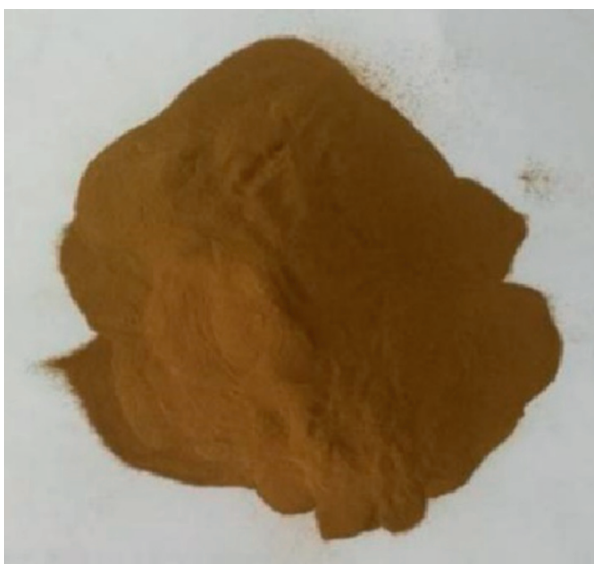

FIgure 1: The lignin.

amount of water, and had a rancid odor. The molecular structure of lignin was determined by FTIR and was found to mainly contain hydroxyl groups $\left(-\mathrm{OH}, 3415 \mathrm{~cm}^{-1}\right)$, C-C bonds $\left(1566 \mathrm{~cm}^{-1}, 783 \mathrm{~cm}^{-1}\right.$, and $\left.654 \mathrm{~cm}^{-1}\right)$, methoxy groups $\left(-\mathrm{OCH}_{3}, 1262 \mathrm{~cm}^{-1}\right)$, carbonyl groups $\left(-\mathrm{CO}, 1052 \mathrm{~cm}^{-1}\right)$, benzene rings $\left(1649 \mathrm{~cm}^{-1}\right)$, and other reactive functional groups. Pure water with a temperature of $20 \pm 0.5^{\circ} \mathrm{C}$, which has a $\mathrm{pH}$ of 6.8 , was used in this study.

2.2. Sample Preparation. The silt sand samples were air-dried and passed through a 2- mm sieve. A certain amount of soil sample and lignin was weighed out, and the samples were mixed with lignin at different ratios $(0 \%, 3 \%, 6 \%, 9 \%, 12 \%$, and $15 \%$ ). Based on the results of the compaction test (see Figure 2), test samples with different lignin contents were prepared based on the optimum moisture content and 96\% of maximum dry density of silt sand treated with lignin, and the samples were mixed well, sealed, and soaked for $12 \mathrm{~h}$. Then, they were poured into a steel mold and test pieces were molded by isostatic pressing. The mold size of the thermal conductivity and dynamic resilient modulus test pieces was diameter $\times$ height $=100 \mathrm{~mm} \times 240 \mathrm{~mm}$. After molding, the samples were stripped with a stripper, which were then placed into a standard curing chamber with a temperature of $20^{\circ} \mathrm{C}$ and relative humidity of $95 \%$ for $28 \mathrm{~d}$. One part of the cured lignintreated and untreated silt sand samples was used directly for the freeze-thaw pretest, while the other part was placed into a highlow alternating temperature test chamber (see Figure 3). The freezing and thawing temperatures in the high-low alternating temperature test chamber were set at $-20^{\circ} \mathrm{C}$ and $20^{\circ} \mathrm{C}$, respectively, the freezing and thawing times were both $24 \mathrm{~h}$, and the number of freeze-thaw cycles was 10. Samples that had undergone 10 freeze-thaw cycles were used for the post-test.

The ring cutter $(61.8 \mathrm{~mm}$ in diameter and $40 \mathrm{~mm}$ in height) was cut vertically into the specimen $(100 \mathrm{~mm}$ in diameter and $200 \mathrm{~mm}$ in height). When leveling both sides of the soil sample, the soil sample shall not be rubbed back and forth with knives. The prepared specimen was used for the permeability test.

The silt sand samples, silt sand treated with lignin samples cured for $28 \mathrm{~d}$, and silt sand treated with lignin 


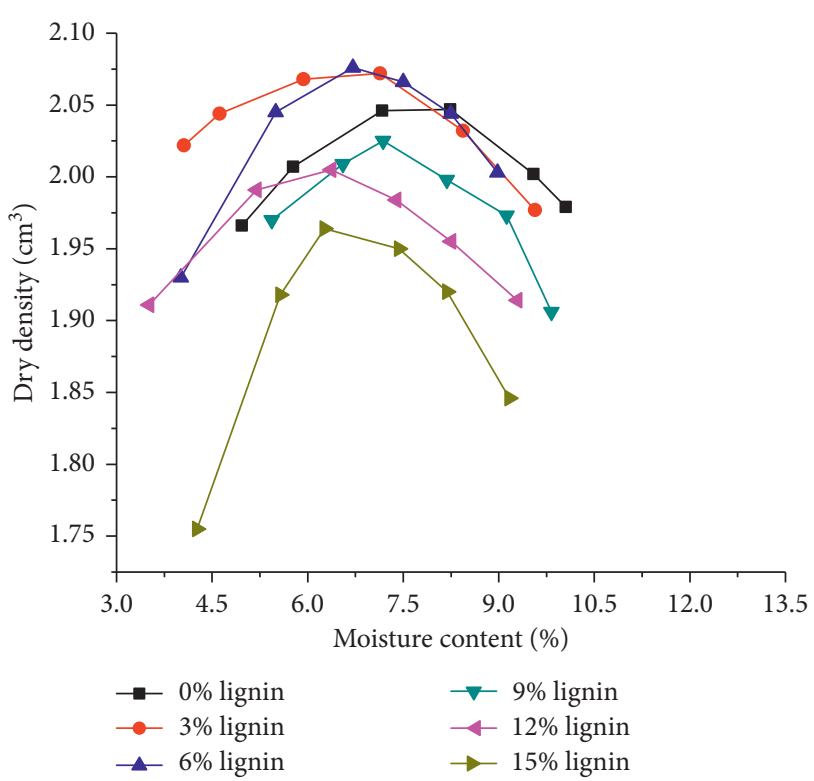

Figure 2: The results of the compaction test.

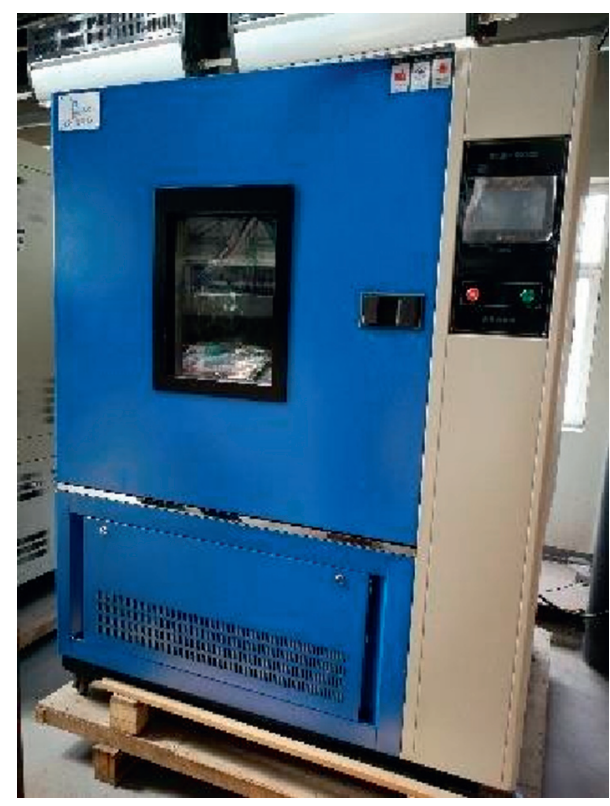

Figure 3: The freeze-thaw test.

samples after $28 \mathrm{~d}$ of curing and 10 freeze-thaw cycles were cut into $20 \mathrm{~mm} \times 20 \mathrm{~mm} \times 20 \mathrm{~mm}$ soil strips using a fine wire saw, placed into a chamber filled with liquid nitrogen, frozen for $10 \mathrm{~min}$, and then dried in a freeze dryer at $-50{ }^{\circ} \mathrm{C}$ under vacuum for more than $24 \mathrm{~h}$. The dried samples were cut with a blade into approximately cuboid test pieces with a base surface of $10 \mathrm{~mm} \times 10 \mathrm{~mm}$ and a height of $5 \mathrm{~mm}$; then, the pieces were removed carefully with tweezers to obtain a fresh, undisturbed surface for SEM and EDS analysis.

The silt sand samples and silt sand treated with lignin samples cured for $28 \mathrm{~d}$ were crushed and air-dried. A certain amount of air-dried sample was weighed out and grounded to powder using an agate mortar and then passed through a $0.075 \mathrm{~mm}$ sieve for $\mathrm{pH}$, FTIR, and XRD analysis. The powdered sample for XRD analysis was also mounted on a glass slide, with care taken to ensure that the cavity of the glass slide was filled with the sample, and sample surface was flat, not loose, and had no falling particles.

2.3. Testing Methods. The thermal conductivity of silt sand treated with lignin was measured using a thermal conductivity meter (see Figure 4) manufactured by Hot Disk, Sweden. The measurement range of thermal conductivity meter was $0.005-500 \mathrm{~W} \cdot \mathrm{m}^{-1} \mathrm{~K}^{-1}$, accuracy: $\pm 3 \%$, sensor type: Kapton (polyimide) film, and testing time: 1-2560 s. When measuring the thermal conductivity of the material, the film-coated nickel spiral probe was sandwiched between two samples. During the test, the resistance changes of the probe were recorded, and the temperature changes with time detected by the probe during the test were systemically established based on the level of resistance.

The loading sequence of repeated triaxial test was worked out according to the NCHRP 1-28A and the specification [21]. The repeated loading test of samples was finished using DTS 30 universal testing machine (see Figure 5) manufactured by Pavetest Company, Italy. The confining pressure was applied by air pressure loading. The vertical loading mode adopts half-vector pulse loading. The loading frequency is $10 \mathrm{~Hz}$, the loading time is $0.2 \mathrm{~s}$, and the loading interval is $0.8 \mathrm{~s}$. The data acquisition and analysis was completed by Testlab software.

The $10 \mathrm{~g}$ sieved soil sample and $50 \mathrm{~mL}$ distilled water were mixed in a beaker. The mixture was left to rest for 1 hour. The $\mathrm{pH}$ values of the mixture were measured by a pHS25 meter.

The samples were adhered to a small film using epoxy resin with the fresh cross section facing upwards, then fixed firmly to a small copper platform with double-sided tape, placed in a vacuum evaporation coater (see Figure 6(a)), and sprayed with gold film. A scanning electron microscope (TESCAN MAR3) (see Figure 6(b)) was used for image acquisition of the coated specimens. Energy dispersive X-ray spectroscopy (Oxford X-MaxN50) was used to determine the chemical elements of the specimens. The types of elements were determined from the energy values, and the element content was determined based on the intensity analysis of the energy spectrum.

A mortar was used to grind $0.2 \mathrm{~g}$ of $\mathrm{KBr}$ to $2.5 \mathrm{um}$ or less, and the ground powder was placed in a powder press mold and pressed for $10 \mathrm{~s}$ to produce the background sample. Then, $0.015-0.02 \mathrm{~g}$ of dried sample was mixed with $0.2 \mathrm{~g}$ of $\mathrm{KBr}$ and grounded with a mortar to less than $2.5 \mathrm{um}$, and the ground powder was placed in a powder press mold and pressed for about $10 \mathrm{~s}$ to produce the test sample. After warming up the Nicolet AVATAR 380 spectrometer, the background sample was loaded, followed by sample testing to collect the infrared spectrum for comparison and analysis.

The silt sand and silt sand treated with lignin samples were mounted onto the central frame on the goniometer stage of the D-2700 X-ray diffractometer, and the X-ray counters around the goniometer stage received the diffraction from the samples, which was converted to an 


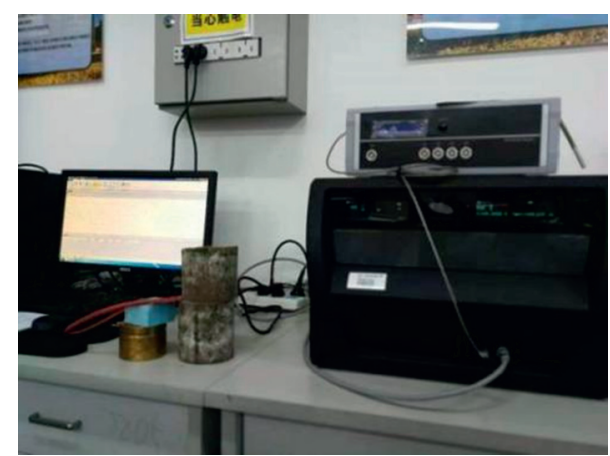

FIgURE 4: The thermal conductivity test.

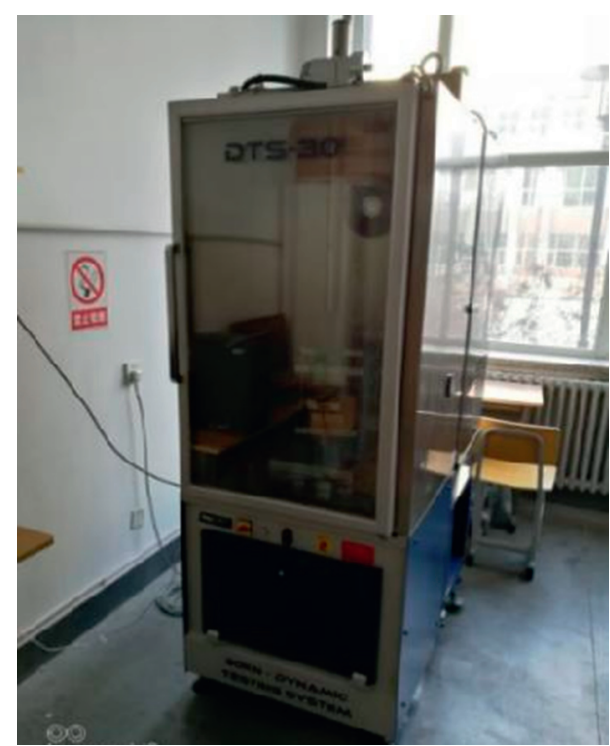

Figure 5: The repeated triaxial test.

electrical signal and inputted into the recorder. Operating conditions: $\mathrm{Cu}-\mathrm{K} \alpha$ target, wavelength $\lambda=1.5148 \AA$, voltage $35 \mathrm{kV}$, current $25 \mathrm{~mA}, 2 \theta$ range $5^{\circ}-60^{\circ}$, and scanning rate $1^{\circ} \%$ $\min$.

\section{Results and Analysis}

3.1. $p H$. Figure 7 shows the $\mathrm{pH}$ values of the treated silt sand with different amounts of lignin. The $\mathrm{pH}$ value increased rapidly at first and then stabilized between 10 and 11. Although the silt sand treated with lignin was alkaline, it was lower than that of lime treated soils [12], which can reduce the damage to the soil and the adverse effects on the environment.

3.2. Thermal Conductivity. As shown in Figure 8, the thermal conductivity of silt sand treated with lignin decreased with increasing lignin content before and after freeze-thaw. After freeze-thaw, the thermal conductivity of silt sand treated with $0 \%, 3 \%, 6 \%, 9 \%, 12 \%$, and $15 \%$ lignin content decreased by $8.9 \%, 6.1 \%, 5.3 \%, 4.0 \%, 2.6 \%$, and $2.3 \%$, respectively (see Figure 8 ). The freeze-thaw action led to the reduction in the thermal conductivity of silt sand treated with lignin, and this finding is similar to that reported in the literature [22].

3.3. Dynamic Resilient Modulus. The dynamic resilient modulus of silt sand treated with lignin under confining pressures of $15 \mathrm{kPa}, 30 \mathrm{kPa}, 45 \mathrm{kPa}$, and $60 \mathrm{kPa}$ was tested. The results are shown in Figures 9(a)-9(d). The dynamic resilient modulus of silt sand treated with lignin increased with increasing confining pressure.

As shown in Figure 9, before and after freeze-thaw, the dynamic resilient modulus of silt sand treated with lignin first increased and then decreased with increasing lignin content. A comparison of the results before and after freezethawing shows that the freeze-thaw action resulted in the decrease of dynamic resilient modulus of silt sand treated with lignin. As lignin content increased from $0 \%$ to $15 \%$, the dynamic resilient modulus decreased by $30.3 \%, 29.6 \%$, $25.0 \%, 26.0 \%, 29.5 \%$, and $32.8 \%$, respectively, when the confining pressure was $30 \mathrm{kPa}$. The mixing of lignin into silt sand effectively increased the deformation resistance of the soil under freeze-thaw conditions. However, the addition of lignin is more than the optimum content, which is disadvantageous to the improvement of soil anti-deformation ability. The optimum lignin content for silt sand in the selected areas was about $6 \%$.

3.4. Permeability. As shown in Figure 10, before and after freeze-thaw, the permeability of silt sand treated with lignin decreased with increasing lignin content. A comparison of the results before and after freeze-thawing shows that the freeze-thaw action resulted in the increase of permeability of silt sand treated with lignin. As lignin content increased from $0 \%$ to $15 \%$, the increase value of permeability coefficient is $3.66 \times 10^{-5}, 3.77 \times 10^{-6}, 2.05 \times 10^{-6}, 0.91 \times 10^{-6}$, $5.03 \times 10^{-6}$, and $5.09 \times 10^{-6}$, respectively. The increase rate of permeability of silt sand treated with lignin is obviously smaller than that of silt sand. The results show that the addition of lignin to silt sand can effectively improve the frost resistance of soil.

3.5. SEM. As shown in Figure 11(a), before freeze-thaw, the soil particles of silt sand were tightly connected and the microstructure was in a compact state. As shown in Figure 11(b), after freeze-thaw, the connections among the soil particles of the silt sand were broken, the microstructure was loosely arranged, and a large number of cracks and pores had appeared. This implies that silt sand has poor frost resistance.

As shown in Figure 12(a), before freeze-thaw, the soil particles of silt sand treated with lignin were tightly connected, and the microstructure was in a compact state. As shown in Figure 12(b), after freeze-thaw, the soil particles of silt sand treated with lignin remained connected without obvious fracture, the microstructure was relatively compact, and there were a few cracks and pores. As shown in Figure 12(c): when the microstructure of the freeze-thawed silt sand treated with lignin was magnified by 5000 times, the 


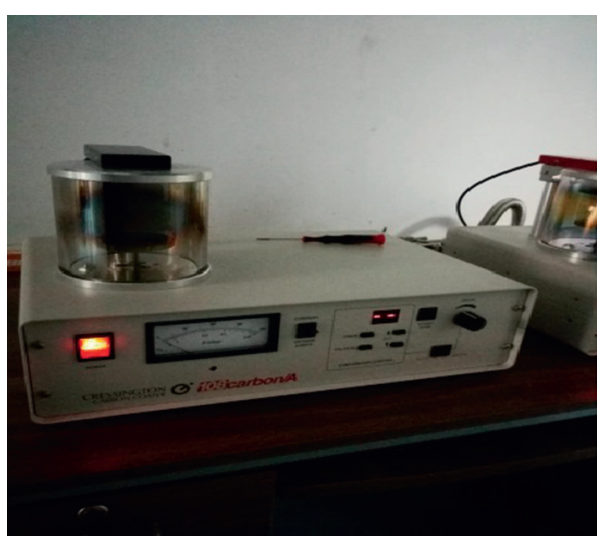

(a)

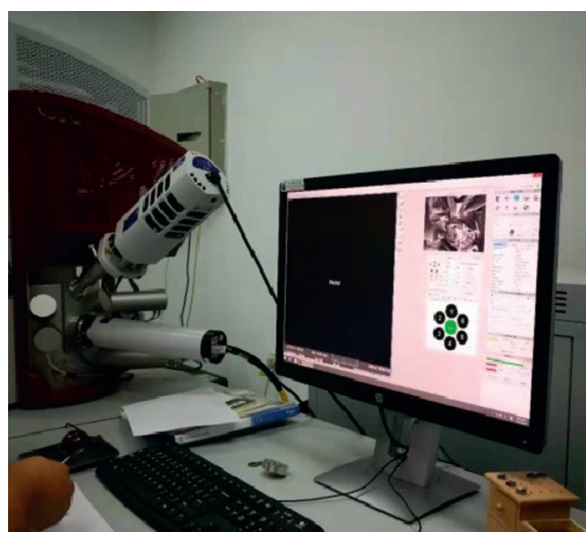

(b)

FIgure 6: The SEM and EDS test.

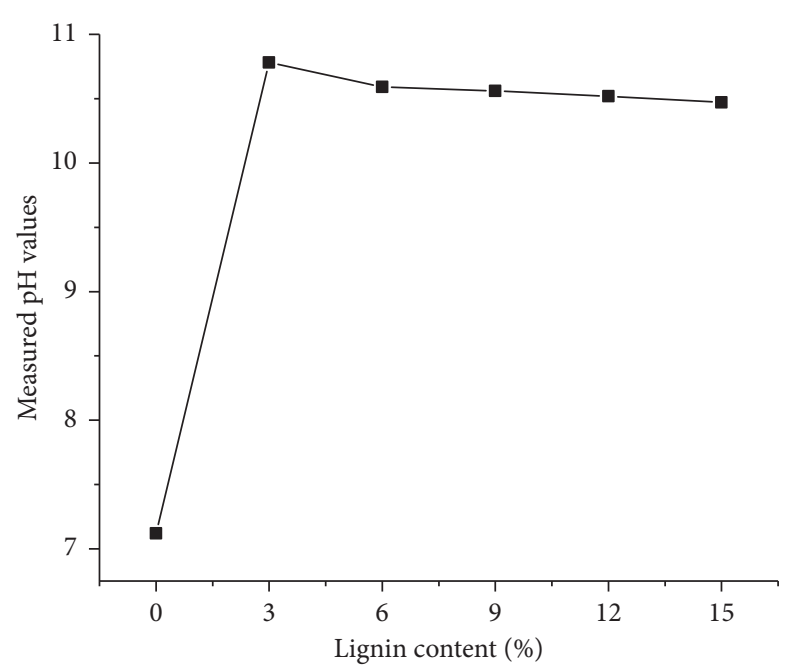

Figure 7: Effect of lignin content on the $\mathrm{pH}$ values.

soil particles were clearly seen to be encapsulated by cementitious material, and the interparticle pores were also filled with cementitious material.

The increase in soil permeability after freeze-thaw can be attributed to the presence of cracks and pores. When lignin was mixed with silt sand, the thermal conductivity and permeability of the soil mass decreased and the dynamic resilient modulus increased, which can be attributed to the encapsulation of soil particles and filling of interparticle pores by cementitious material.

3.6. EDS. The SEM images of silt sand and silt sand treated with lignin were selected to test the atomic percentages, and the mean values of the atomic percentages were calculated. The results are shown in Figure 13. Comparison of the test results between silt sand and silt sand treated with lignin revealed that $\mathrm{C}$ and $\mathrm{Na}$ were added to the element composition of the latter, and the atomic percentages of the other elements had decreased by a certain extent. Since $\mathrm{C}$ and $\mathrm{Na}$ are the main constituents of sodium lignosulfonate, it follows that no other new chemical elements were produced by mixing lignin into silt sand.

3.7. XRD. Figure 14 shows the XRD patterns of silt sand and silt sand treated with lignin. The main minerals in silt sand were Quartz $\left[\mathrm{SiO}_{2}\right]$, orthoclase $\left[\mathrm{K}\left(\mathrm{AlSi}_{3}\right) \mathrm{O}_{8}\right]$, albite low $\left[\left(\mathrm{Na}\left(\mathrm{AlSi}_{2} \mathrm{O}_{8}\right)\right]\right.$, montmorillonite $\left[(\mathrm{Ca}) 0.2(\mathrm{Al}, \mathrm{Mg})_{2}\left(\mathrm{Si}_{4} \mathrm{O}_{10}\right)\right.$ $\left.(\mathrm{OH})_{2} \cdot 4 \mathrm{H}_{2} \mathrm{O}\right]$, and illite $\left[\mathrm{KAl}_{2}\left(\mathrm{Si}_{3} \mathrm{Al}\right) \mathrm{O}_{10}(\mathrm{OH})_{2}\right]$. By comparing the XRD patterns of the two soil samples, we can see that the diffraction peaks of silt sand treated with lignin and silt sand appeared at essentially the same positions, and no new peaks were produced, which indicates that no new mineral components were produced in the silt sand treated with lignin. This finding is in good agreement with the literature [19].

3.8. FTIR. Figure 15 shows the infrared spectra of lignin, silt sand, and silt sand treated with lignin. The silt sand contained mainly Al-O-H bonds $\left(3617 \mathrm{~cm}^{-1}\right.$ and $\left.3620 \mathrm{~cm}^{-1}\right)$, $-\mathrm{OH}$ bonds in water molecules $\left(3693 \mathrm{~cm}^{-1}, 3425 \mathrm{~cm}^{-1}\right.$, and 


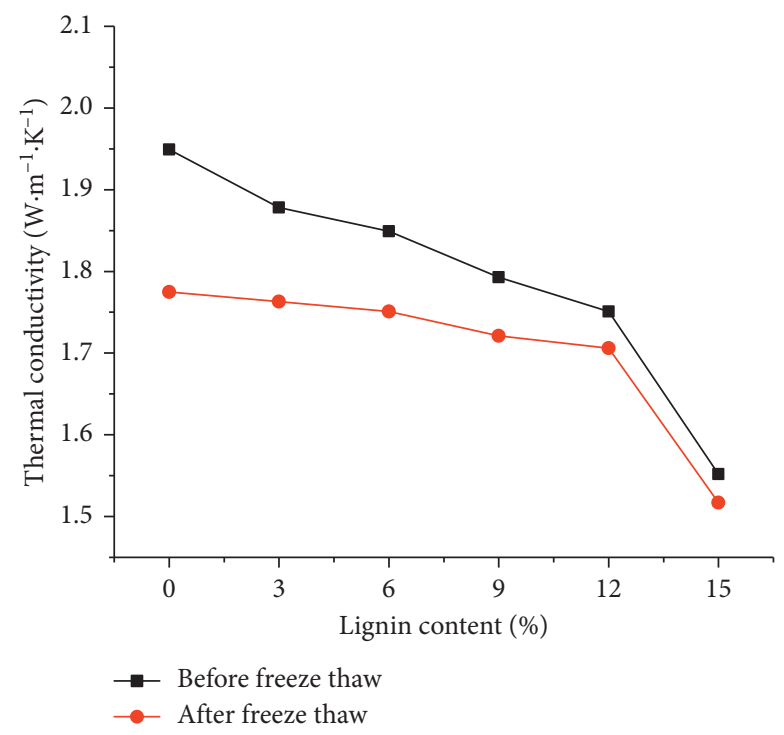

Figure 8: Effect of freeze-thaw and lignin content on the thermal conductivity.

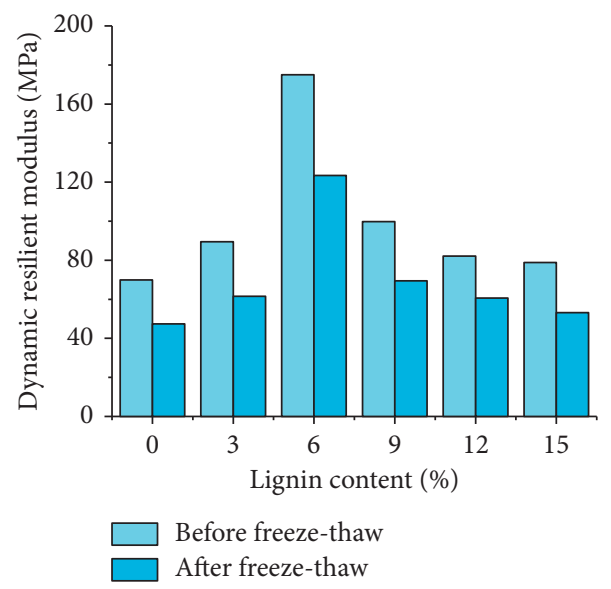

(a)

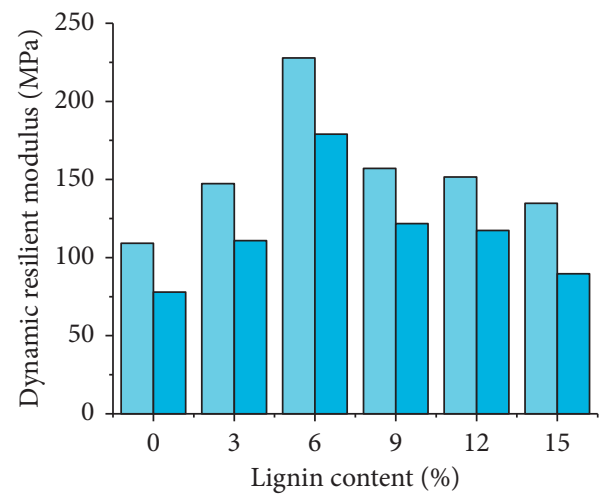

Before freeze-thaw After freeze-thaw

(c)

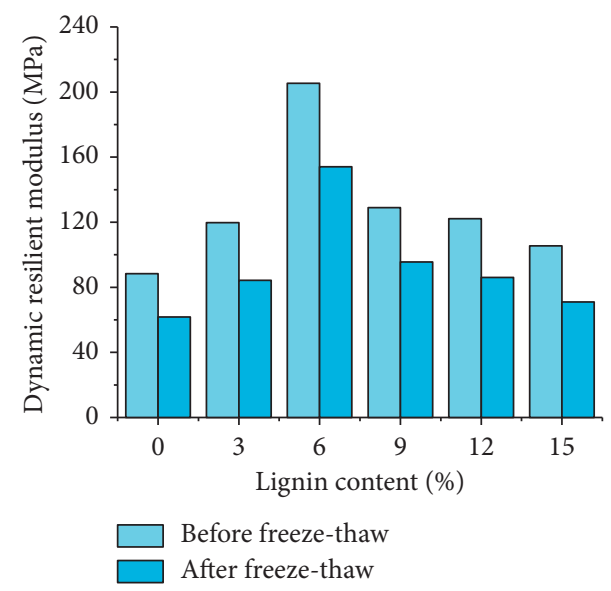

(b)

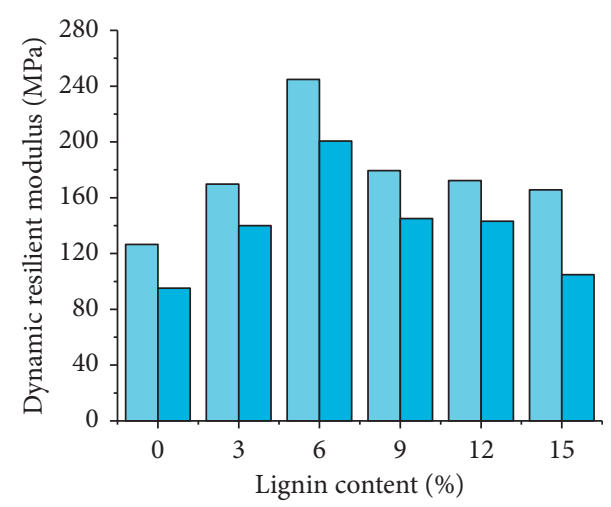

Before freeze-thaw After freeze-thaw

(d)

FIGURE 9: Effect of freeze-thaw and lignin content on dynamic resilient modulus. 


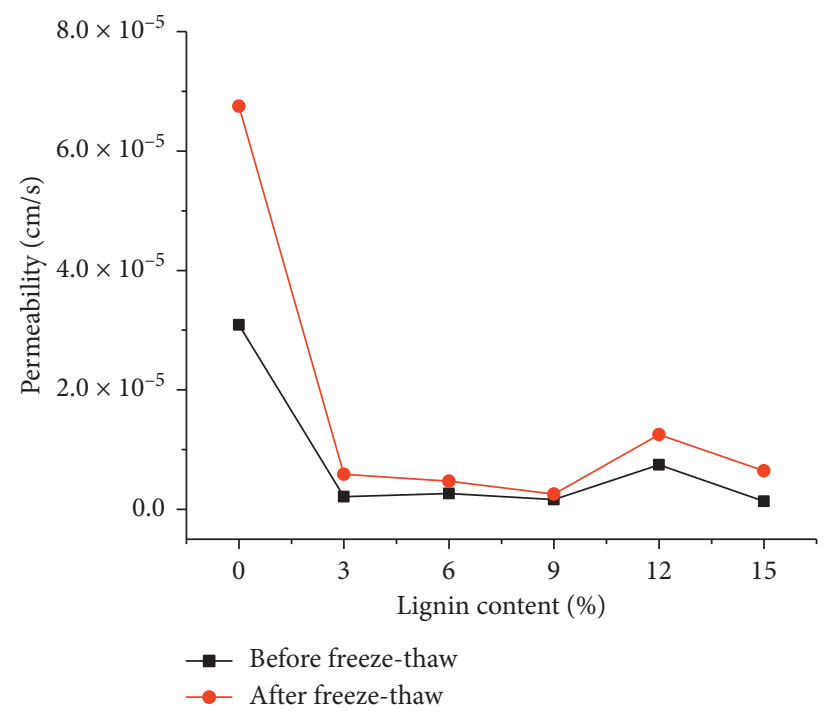

Figure 10: Effect of freeze-thaw and lignin content on the permeability.

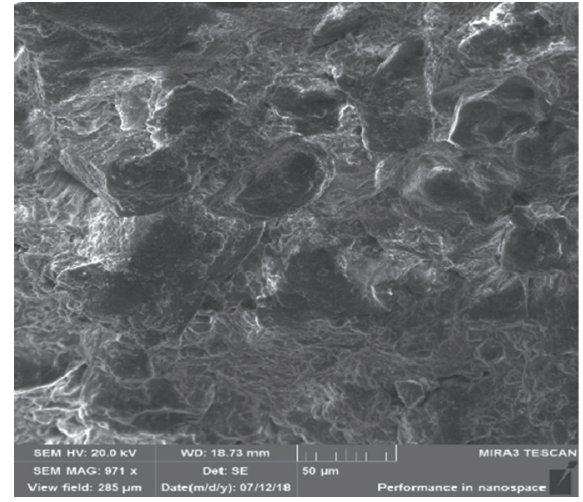

(a)

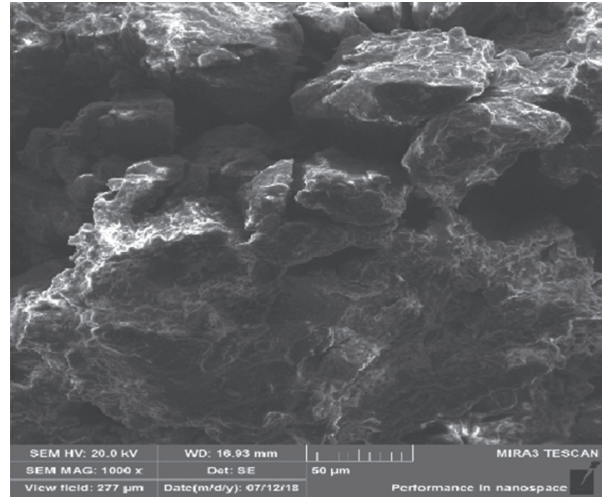

(b)

FIGURE 11: SEM images of silt sand before and after freeze-thaw.

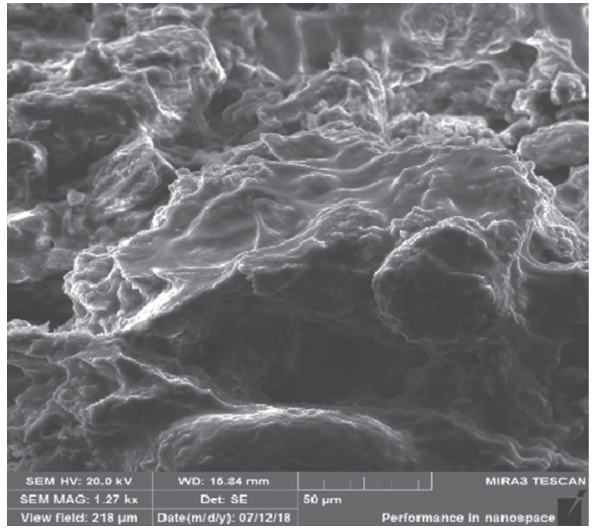

(a)

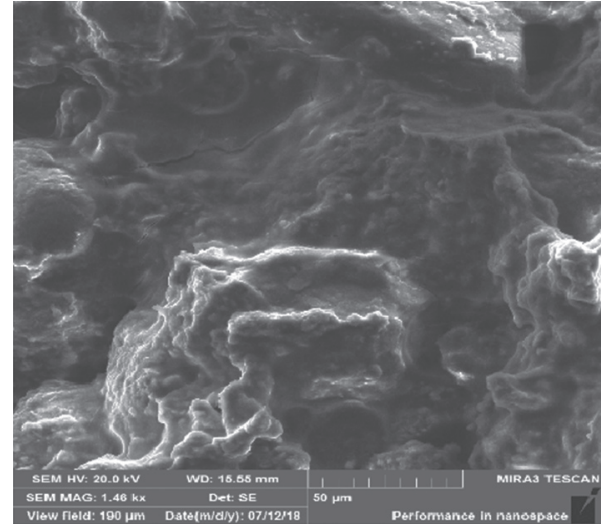

(b)

Figure 12: Continued. 


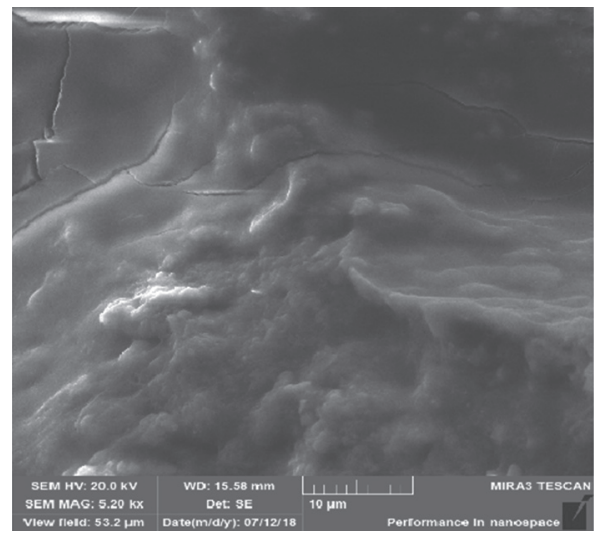

(c)

FIGURE 12: SEM images of silt sand treated with lignin before and after freeze-thaw.

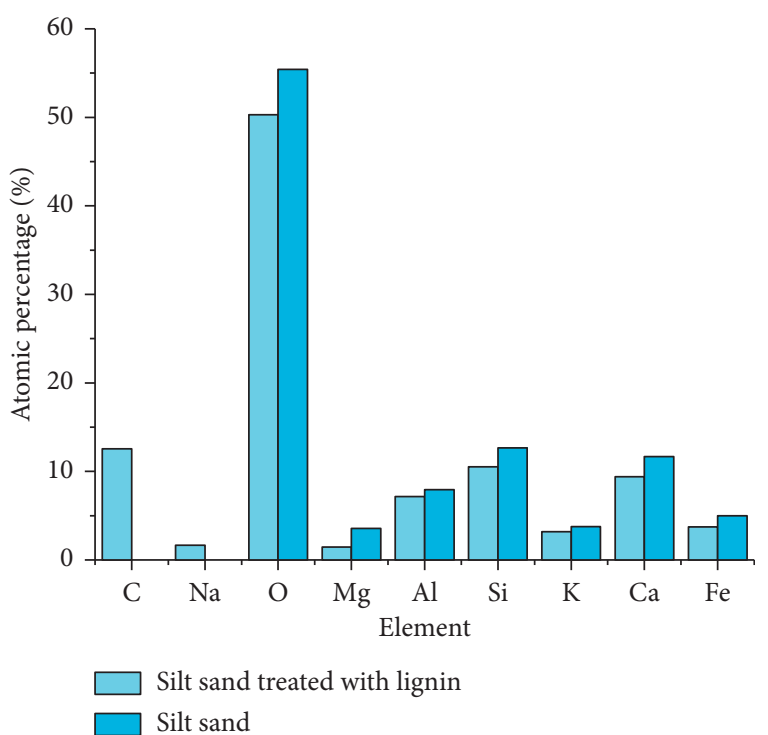

FIGURE 13: EDS analysis of silt sand and silt sand treated with lignin.

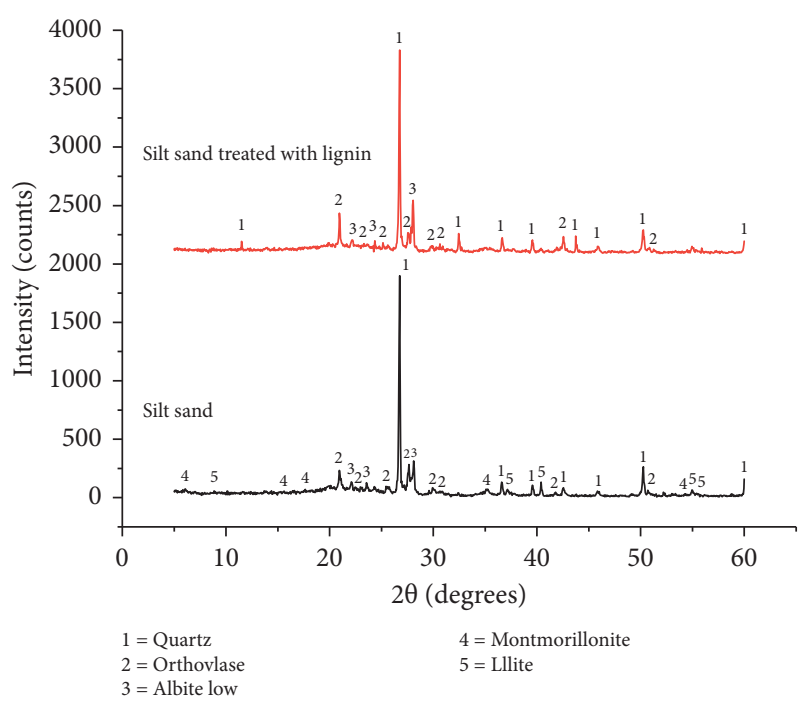

FIGURE 14: XRD analysis of silt sand and silt sand treated with lignin.

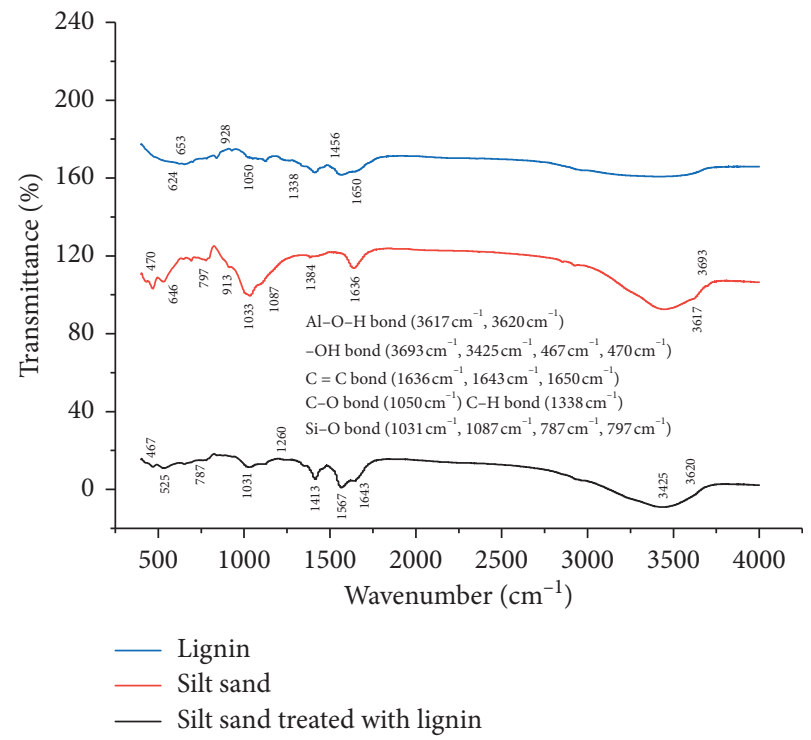

FIGURE 15: Infrared spectrum of silt sand and silt sand treated with lignin.

$\left.467 \mathrm{~cm}^{-1}\right)$, and Si-O bonds $\left(1087 \mathrm{~cm}^{-1}, 787 \mathrm{~cm}^{-1}\right.$, and $\left.797 \mathrm{~cm}^{-1}\right)$. The types of functional groups found in silt sand treated with lignin were almost equal to the sum of the functional groups found in lignin and silt sand, thus indicating that mixing lignin into silt sand did not result in the creation of new functional groups.

\section{Conclusions}

This paper analyzed the effects of freeze-thaw and lignin content on the macroscopic engineering properties and microstructural characteristics of silt sand treated with lignin, and the following conclusions were drawn:

(1) As lignin content increased from $0 \%$ to $15 \%$, before freeze-thaw, the thermal conductivity and permeability of silt sand treated with lignin gradually decreased and $\mathrm{pH}$ value stabilized between 10 and 11, while dynamic resilient modulus decreased when the 
lignin content was greater than 6\%; after freeze -thaw, the thermal conductivity and permeability of silt sand treated with lignin gradually decreased, and its dynamic resilient modulus still decreased when lignin content was greater than $6 \%$. The optimum lignin content for silt sand from Jilin Province, China, is about $6 \%$.

(2) The freeze-thaw action resulted in the decrease of the thermal conductivity and dynamic resilient modulus of silt sand treated with lignin, whereas the increase of permeability. Before freeze-thaw, silt sand and silt sand treated with lignin showed compact microstructure. After freeze-thaw, many cracks and pores appeared in the microstructure of silt sand, and the particles were scattered, whereas only a few cracks and pores were observed in the microstructure of silt sand treated with lignin due to the encapsulation of soil particles by cementitious material.

(3) The results of EDS, XRD, and FTIR analyses showed that no new chemical elements, mineral components, or functional groups were produced by mixing lignin with silt sand.

(4) The mechanism by which lignin improved the macroscopic engineering properties of silt sand involved the cementitious material produced by mixing lignin with the soil, which encapsulated the surface of soil particles and filled the interparticle pores, thereby increasing the structural strength of the soil mass.

\section{Data Availability}

All data included in this study are available from the corresponding author upon request.

\section{Conflicts of Interest}

The authors declare that there are no conflicts of interest regarding the publication of this paper.

\section{Acknowledgments}

This research was financially supported by the project of Education Department of Jilin Province (JJKH20210281KJ), National Undergraduate Innovation and Entrepreneurship Training Program (202010191041), and project of Ministry of Housing and Urban-Rural Development (2017-K4-004).

\section{References}

[1] G. Tan, W. Wang, Y. Cheng, Y. Wang, and Z. Zhu, "Establishment of complex modulus master curves based on generalized sigmoidal model for freeze-thaw resistance evaluation of basalt fiber-modified asphalt mixtures," Polymers, vol. 12, no. 8, p. 1698, 2020.

[2] W. Wang and G. Tan, "Study on viscoelastic properties of asphalt mixtures incorporating SBS polymer and basalt fiber under freeze-thaw cycles," Polymers, vol. 12, p. 1804, 2020.

[3] Y. Cheng, H. Li, W. Wang, L. Li, and H. Wang, "Laboratory evaluation on the performance degradation of styrene- butadiene-styrene-modified asphalt mixture reinforced with basalt fiber under freeze-thaw cycles," Polymers, vol. 12, no. 5, p. 1092, 2020.

[4] J. Liu, T. Wang, and Y. Tian, "Experimental study of the dynamic properties of cement- and lime-modified clay soils subjected to freeze-thaw cycles," Cold Regions Science and Technology, vol. 61, no. 1, pp. 29-33, 2010.

[5] M. Yıldız and A. S. Soğanc1, "Effect of freezing and thawing on strength and permeability of lime-stabilized clays," Scientia Iranica, vol. 19, no. 4, pp. 1013-1017, 2012.

[6] A. Aldaood, M. Bouasker, and M. Al-Mukhtar, "Impact of freeze-thaw cycles on mechanical behaviour of lime stabilized gypseous soils," Cold Regions Science and Technology, vol. 99, pp. 38-45, 2014.

[7] T. Shibi and T. Kamei, "Effect of freeze-thaw cycles on the strength and physical properties of cement-stabilised soil containing recycled bassanite and coal ash," Cold Regions Science and Technology, pp. 106-107, 2014.

[8] A. Hotineanu and M. Bouasker, "Effect of freeze-thaw cycling on the mechanical properties of lime-stabilized expansive clays," Cold Regions Science and Technology, vol. 119, pp. 36-45, 2015.

[9] Y. Liu, Q. Wang, S. Liu et al., "Experimental investigation of the geotechnical properties and microstructure of lime-stabilized saline soils under freeze-thaw cycling," Cold Regions Science and Technology, vol. 161, pp. 32-42, 2019.

[10] S. Zhanga and X. Yanga, "Experimental study on improving the engineering properties of coarse grain sulphate saline soils with inorganic materials," Cold Regions Science and Technology, vol. 170, Article ID 102909, 2020.

[11] R. S. Rollings, J. P. Burkes, and M. P. Rollings, "Sulfate attack on cement-stabilized sand," Journal of Geotechnical and Geoenvironmental Engineering, vol. 125, no. 5, pp. 364-372, 1999.

[12] F. Zhu, Z. Li, W. Dong, and Y. Ou, "Geotechnical properties and microstructure of lime-stabilized silt clay," Bulletin of Engineering Geology and the Environment, vol. 78, no. 4, pp. 2345-2354, 2018.

[13] B. Indraratna, R. Athukorala, and J. Vinod, "Estimating the rate of erosion of a silty sand treated with lignosulfonate," Journal of Geotechnical \& Geoenvironmental Engineering, vol. 139, no. 5, pp. 701-714, 2012.

[14] J. S. Tingle and R. L. Santoni, "Stabilization of clay soils with nontraditional additives," Transportation Research Record, vol. 1819, pp. 72-84, 2003.

[15] H. Ceylan, K. Gopalakrishnan, and S. Kim, "Soil stabilization with bioenergy coproduct," Transportation Research Record: Journal of the Transportation Research Board, vol. 2186, no. 1, pp. 130-137, 2010.

[16] S. Kim, K. Gopalakrishnan, and H. Ceylan, "Moisture susceptibility of subgrade soils stabilized by lignin-based renewable energy coproduct," Journal of Transportation Engineering, vol. 138, no. 11, pp. 1283-1290, 2012.

[17] B. Indraratna, R. Athukorala, and J. Vinod, "Estimating the rate of erosion of a silty sand treated with lignosulfonate," Journal of Geotechnical and Geoenvironmental Engineering, vol. 139, no. 5, pp. 701-714, 2013.

[18] Q. Chen, B. Indraratna, J. Carter, and C. Rujikiatkamjorn, “A theoretical and experimental study on the behaviour of lignosulfonate-treated sandy silt," Computers and Geotechnics, vol. 61, pp. 316-327, 2014.

[19] T. Zhang, G. Cai, S. Liu, and A. J. Puppala, "Engineering properties and microstructural characteristics of foundation silt stabilized by lignin-based industrial by-product," KSCE 
Journal of Civil Engineering, vol. 20, no. 7, pp. 2725-2736, 2016.

[20] T. Zhang, G. Cai, and S. Liu, "Application of lignin-based byproduct stabilized silty soil in highway subgrade: a field investigation," Journal of Cleaner Production, vol. 142, pp. 4243-4257, 2017.

[21] National Research Council, NCHRP 1-28a, Harmonized Test Methods for Laboratory Determination of Resilient Modulus for Flexible Pavement Design-Final Report, National Research Council, Washington, DC, USA, 2003.

[22] H. Jiang, F. Niu, E. Wang, Q. Ma, and L. Cheng, "Study on the thermophysical properties of clay under repeated freezing and thawing," Pure and Applied Geophysics, vol. 177, no. 11, pp. 5349-5366, 2020. 